\title{
Internal Podalic Version an Option for Developing Countries
}

\author{
SF NARGIS ${ }^{\mathrm{a}}$, R ARA ${ }^{\mathrm{b}}, \mathrm{G} \mathrm{ARA}^{\mathrm{C}}$, J BEGUM ${ }^{\mathrm{d}}$
}

\begin{abstract}
Summary:
Objective: To study the role of internal podalic version (IVP) in the management of transverse lie with fetal demise in labour and to assess the success and outcome of this almost obsolete procedure in obstetrics. Materials and Methods: Quasi experimental study was done in Shaheed Ziaur Rahman Medical College and Mohammad Ali Hospital, Bogra from January 2001 to December 2006. Results: Within this period total 180 cases transverse lie with intrauterine fetal death (IUFD) were studed. All these case were undiagnosed transverse lie with IUFD in labour and admitted in the hospital through the emergency department. In 60 cases IPV and in 120 cases lower uterine segment caesarean section (LUCS) were done to deliver the dead
\end{abstract}

\section{Introduction:}

Version is defined as a shift in the position of the fetus inside of the uterus, either occurring naturally (spontaneous version) or as performed by a doctor to facilitate delivery. Internal version is an ancient procedure and it was extensively practiced by Hippocrates, who recommended internal cephalic version for all presentations other than head ${ }^{1}$. Aetius , Celsus and others at different times pointed out the fallacies of Hippocratic teaching and emphasized the advantage of internal podalilc version (IPV). IPV continued to be in favour till the sixteen century. In modern obstetrics caesarean section is the method of choice for the delivery of babies in transverse lie. The role of IPV followed by breech extraction is only limited to mal presentation or abnormal lie of the second twin.

In the case of singleton transverse lie it is contra indicated with a live fetus with intact membranes ${ }^{1,2}$.

a. Dr. Shamim Fatema Nargis, Associate Professor, Obstetrics and Gynaecology, SSMC.

b. Dr. Rawshan Ara, Assistant professor, Obstetrics and Gynaecology, SSMC.

c. Dr. Gulshan Ara, Associate Professor, Obstetrics and Gynaecology, SSMC.

d. Dr. Jahanara Begum, Associate Professor, Obstetrics and Gynaecology, SSMC.

Address of Correspondence: Dr Shamim Fatema Nargis, Associate Professor, Obstetrics and Gynaecology, SSMC.

Received: 12 January, 2013

Accepted: 26 December, 2013 fetus. All the cases were more than 37 weeks gestation. Need for per operative and post operative blood transfusion were only $03.33 \%$ in cases where IVP was done, and $41.66 \%$ in those who under went LUCS $(P<.001)$. Hospital stay in IVP group was only 1.3 days where as 10 days for those who under went LUCS $(P<.001)$. Regarding complications it was almost same in both groups. IVP was also very cost effective required some of taka 300 only where as for LUCS it required about 3000 taka. Conclusion: The success rate of IVP is good. It is cost effective, preserve the future fertility and prevent subsequent scar rupture where Antenatal care is poor.

Key words: Transverse lie, Dead foetus, internal podalic version

(J Banagladesh Coll Phys Surg 2014; 32: 16-20)

In the developing countries the maternal mortality rate (MMR) is very high and now in Bangladesh still it is $1.9 / 1000$ live birth. Ninty percent deliveries are conducted at home and only 15\% deliveries are conducted by Skilled Birth Attendants (SBA). Eighty percent maternal death occurred after home delivery ${ }^{3}$.

Rupture uterus is a serious obstetric emergency with high maternal and perinatal mortality rate. The risk of uterine rupture is more in the presence of scarred uterus, lack of adequate antenatal care, low socioeconomic status and unsupervised labour at home. Performing a caesarean section for a dead, previable baby will lead to a scarred uterus increasing the risk of rupture in subsequent pregnancy.

Internal version is always podalic version and is completed with the extraction of the fetus. Before performing internal podalic version cervix must be fully dilated and liquor amni should be adequate for the intra uterine foetal manipulation. Patient should be deeply anaesthetized and in lithotomy position. Full surgical asepsis should be taken. If the podalic pole of the foetus is on the left side of the mother the right hand is to be introduced and vice versa. The hand is to be introduced in a cone shaped manner, it is than pushed up in to the uterine cavity keeping the back of the hand against the uterine wall until the hand reaches the podalic pole. The hand is to pass up to the breech and then along the thigh until a foot is grasped. The identification of the foot is 
done by palpation of the heel and bring down the leg by a steady traction. While the leg is brought down the cephalic pole is pushed up by using the external hand. After one leg is brought down there is no difficulty in deliver the other leg by breech extraction.

IPV is much maligned to produce sepsis, postpartum haemorrage and uterine rupture causes high fetal and maternal morbity and mortality rates itself. In selected cases and in experienced hands IPV is comparatively safe in the developing countries and contribute to reducing the maternal mortality and morbidity by avoiding caesarean section and subsequent uterine rupture ${ }^{4,5}$.

\section{Methodology:}

It is a quasi experimental comparative trial done at Shaheed Ziaur Rahman Medical College and Mohammad Ali Hospital, Bogra from January 2001 to December 2006. The patients with transverse lie with intra uterine death at term admitted during this period were included in the study. In one group IPV was done and in other group caesarean was done to deliver the dead foetus. The mode of delivery either by IPV or by LUCS was recorded. LUCS was done in cases of impacted shoulder, impending rupture, failed attempt at version, and early sign of maternal shock due to obstructed labour or chorioamnionitis, possibility of intra uterine manipulation. LUCS also done in absence of experienced surgeon to perform IPV. Need for blood transfusion, cost effectiveness and hospital stay in two groups were compared. Complications occurred during version or LUCS were noted. Socio demographic details, associated obstertric history and parity were recorded. Complications were measured in terms of
Post Partum Haemorrahage(PPH), para urethral or vaginal tear, rupture uterus, extension of wound or broad ligament haematoma and wound infections.

\section{Results:}

During 2001 to 2006 years almost total 24,000 delivery has occurred at shaheed Ziaur Rahman Medical College and Mohammed Ali Hospital, which is a teaching hospital and tertiary referral centre. Rate of LUCS is about $45 \%$ in this hospital due to different indications. Total percentage of transverse lie admitted within this period is $0.97 \%$ ( 233cases). IPV were done in 60 (25.75\%) cases, LUCS were performed in 120 cases (51.5\%) of transverse lie, 53 cases presented with rupture uterus where laparotomy was done. 6 cases of IPV were in twin gestation. None of them were booked cases. Most cases (86\%) came from rural population. $74.24 \%$ cases were of more than 37 weeks gestation, and 16 cases $(6.8 \%)$ were between 28 to 32 week gestation. 34cases (14.59) were primigravida and the rest 199 (85.40\%) were multigravida. 53\% of the patients were within the age range of 21 to 30 . The groups of patients where IPV (60) was done, 8 (13.33 $\%)$ cases were primigravida and 52 (86.6\%) cases were multigravida. During the procedure of IPV following complications like cervical tears in two cases, in10 cases paraurethral and vaginal tears occurred. In 1 case rupture uterus occurred during version and subtotal hysterectomy was done. Three mothers developed mild post partum haemorrhage and managed conservatively. Only in 2 cases blood transfusion was required. Almost all these patients were discharged from the hospital on the next day of admission.

Table-I

Shows the demography of the patients admitted with transverse lie and management given to them.

\begin{tabular}{|c|c|c|c|}
\hline Total no of obstetric pt admitted & & 24000 & \\
\hline Total no of transverse lie admitted & & 233 & \\
\hline $\begin{array}{l}\text { Age range (in years) } \\
\text { no }\end{array}$ & $\begin{array}{c}15-20 \\
40(17 \%)\end{array}$ & $\begin{array}{c}20-30 \\
123(53 \%)\end{array}$ & $\begin{array}{c}30-40 \\
70(30 \%)\end{array}$ \\
\hline $\begin{array}{l}\text { Parity } \\
\text { no }\end{array}$ & $\begin{array}{c}\text { Primigravida } \\
34\end{array}$ & $\begin{array}{c}\text { Multigravida } \\
199\end{array}$ & \\
\hline $\begin{array}{l}\text { Gestational age } \\
\text { no }\end{array}$ & $\begin{array}{c}28-32 \text { weeks } \\
16\end{array}$ & $\begin{array}{l}\text { 32-36 weeks } \\
44\end{array}$ & $\begin{array}{c}>37 \text { weeks } \\
173\end{array}$ \\
\hline $\begin{array}{l}\text { Management given } \\
\text { no }\end{array}$ & $\begin{array}{c}\text { IPV } \\
60\end{array}$ & $\begin{array}{c}\text { LUCS } \\
120\end{array}$ & Laparotomy \\
\hline
\end{tabular}


In 30 cases, version were done by obstetrician of $>5$ years of experience, 15 cases of version were done by obstetricians of 3 to 5 years experiences and 15 cases were done by junior doctors less than 2 years of experience with the supervision's of the seniors. General anaesthesia was given in all cases.

LUCS done on 20 (16.6\%) cases were primigravid and 100 (83.33) cases were multigravid. During the procedure of LUCS complications like, extension of the uterine incision, broad ligament haematoma and vertical tear in the lower segment involving the vault of the vagina had occurred in 4 cases. 25 cases need blood transfusion both per and post operatively. General anaesthesia or Regional block was given in all the cases. Post operative stitch infection had occurred in 50 cases due to mal handling at home, and all needs secondary suture. But no burst abdomen was found. Mean postoperative hospital stay were 10 days.

\section{Table-II}

Show the difference in demography of the patient in IPV \& LUCS groups.

\begin{tabular}{lccc} 
& IPV $(60)$ & LUCS (120) & Level of significance \\
\hline Mean age & 26.59 & 28 & NS \\
Mean parity & 3.00 & 3.2 & NS \\
Mean gestational age & 38 weeks & 38 weeks & NS \\
\hline
\end{tabular}

NS - not significant

Table-III

\begin{tabular}{|c|c|c|c|}
\hline \multicolumn{4}{|c|}{ Show the difference of variable in between the IPV and LUCS } \\
\hline & IPV(60) & LUCS (120) & Level of significance \\
\hline SAB/GA given & $100 \%$ cases & $100 \%$ cases & \\
\hline Blood transfusion & 02 (3.3\%) & $50(41.66 \%)$ & $* * *$ \\
\hline Hospital stay & 1.3 days & 10 days & $* * *$ \\
\hline cost & 300 taka & 3000taka & $* * *$ \\
\hline
\end{tabular}

NS: - not significant

Table-IV

\begin{tabular}{|c|c|c|c|}
\hline & IPV & LUCS & Level of significance \\
\hline PPH (mild to moderate) & 02 cases & 05 cases & NS \\
\hline Para urethral or vaginal tear & 10 & 10 & NS \\
\hline Cervical tear & 02 & 00 & NS \\
\hline Rupture uterus & 01 & 00 & NS \\
\hline Extension of uterine wound or Broad ligament haematoma & 00 & 04 & NS \\
\hline Stitch infections need secondary suture & 00 & 50 & $* * *$ \\
\hline
\end{tabular}

NS: - not significant 


\section{Discussion:}

Analyzing the cases of transverse lie which were managed by IPV, none of these 60 cases had any form of antenatal care. They admitted in the hospital with complications when they could not deliver at home after various hours of labour pain. Due to improper Antenatal care there is high incidence of undiagnosed malpresentation in labour, and moreover due to inadequate transport facilities there is delay in approaching at the tertiary health centre. These complicated, undiagnosed cases of transverse lie report to the hospital in advanced labour and by this time it is not always possible to salvage their babies and even some times these mothers also. During this study period total 24000 patients admitted in this hospital and the incidence of transverse lie is $0.97 \%$ which is higher than normal incidence because it is a tertiary referral hospital. In our study of total 233 case of transverse lie admitted, out of which $38.83 \%$ (60) under gone IPV procedure, $51.50 \%$ (120) had LUCS and 22.74 \%( 53) cases comes with ruptured uterus.

Amita mahedru, Onome Ogueh, Ketan Gajjar, Charu Rawat in their study performed IPV in $15.8 \%$ and LUCS in $73.5 \%$ of total transverse lie admissions. $10.7 \%$ patient presented with rupture uterus in their study. Demography shows that $83 \%$ patients came from rural population, $88 \%$ were multipara, none of them were booked case, and 51\% cases were more than 37 weeks gestational age which is similar to our study ${ }^{1}$. We found that $86 \%$ patient comes from rural area, $74.25 \%$ patient had gestational age more than 37 weeks, and none of them had any Antenatal check up except immunization against tetanus. Patient with rupture uterus is more (53cases) in our series. Chauhan AR, et al shows on their study from 1986 to 1991 and 1992 to 1997 that the incidence of transverse lie admitted was same in both series ( $0.4 \%$ and $0.32 \%$ ) but the number of IPV performed in the $2^{\text {nd }}$ series reduced to almost halves. Most the IPV performed on the patient age between 20 to 30 years of age and on second gravida same as our study ${ }^{4,6}$. Dufour et al conducted a retrospective study of 35 cases of IPV followed by breech extraction of second twin. They found that Internal Version together with external version is the only alternative to LUCS allowing rapid delivery of the second twin. Maternal prognosis is excellent and foetal out come is good if contraindications of IPV are avoided ${ }^{7}$. Rabinovici et al conducted a prospective study for management of second nonvertex twin. 60 twin deliveries after the $35^{\text {th }}$ gestational week with vertex-breech and vertextransverse presentation were managed according to randomized protocol of vaginal or abdominal delivery. Of 21 patient vertex transverse presentations 12 were delivered by LUCS. They found there was a significantly higher incidence of febrile morbidity in LUCSgroup ${ }^{8}$. In our study regarding many complications following IPV and LUCS are similar but in case of LUCS stitch infections need secondary suture in 50 cases and this complication is statistically significantly higher $(\mathrm{p}<0.001)$. pre operative and post operative blood transfusion is needed only 3.33\% in cases of IPV and $41.66 \%$ in cases of LUCS operation, which is statistically significant $(<0,001)$.

\section{Conclusions:}

In earlier years internal podalic version was performed on all stillbirths, nonviable babies, second twin and in a few singleton pregnancies in which the babies were of low birth weight and were preterm. However with improved neonatal facilities today, low birth weight and preterm babies have a better chance of survival. This combined with increased safety of the caesarean section, there is a changing trend in the mode of delivery of transverse lie more in favour of LUCS. Above all with the decrease trend for IPV, most obstetricians have not even seen it being performed. So caesarean section is performed even on dead babies and in large number of second twins. But rural patients who do not have health care facilities, LUCS with the increase risk of placenta previa, rupture uterus in subsequent pregnancy is always a threat.

We believe that though caesarean section is certainly a better option for singleton viable babies in transverse lie, IPV has a role to play in the delivery of second twin. It may also be attempted in the delivery of nonviable and dead babies in the absence of contraindications, especially in developing countries.

\section{References:}

1. Mahendru A, Ogueh O, Gajjar K, Rawat C. Role of Internal Podalic Version In Developing Countries. The internet Journal of Gynaecology and Obstetrics, 2006; 6(1): 94-96. 
2. Mahajan N,Gaikwad N,Solomon M,Mahajan K, and Kothari N.(2009), Internal podalic version for neglected shoulder presentation with fetal demise. BJOG: An International Journal of Obstetrics \& Gynaecology, 2006; 116: 1801-1804.

3. New survey finds Maternal Mortality Ratio Drop $40 \%$ in Bangladesh.www.icddrb.org/media-centre/news/maternal mortality in Bangladesh.

4. Chauhan AR et al, Journal of postgraduate medicine. Is internal podalic version a lost art? 2001; 47(1): 15-8.

5. Chandra M;Chaturvedi B. Internal podalic version a forgotten art; Journal of Obstetrics and Gynaecology of India. 2002; 52(3):80-2.
6. AR Chauhan, TT Singhal, VS Raut. Is internal podalic version a lost art? Optimum mode of delivery in transeverse lie. J postgrad Med 2001; 47:15.

7. Dufour P,Vinatier D, Bennai S, Tordjeman N,Ducloy JC, Nihous F, et al. Internal version and breech extraction of second twin. A series of 35 cases. J Gynaecol Obstet Biol Repord (Paries) 1996; 25; 617-622.

8. Rovinovici J, Barkai G,Reichman B. Randomized management of the second nonvertex twin: Vaginal delivery or Caesarean section. Am J Obstet Gynecol1987; 156:52-56. 